\title{
Evaluasi Kinerja Aset Fasilitas Wisata Domba di Kabupaten Garut
}

\author{
Asset Facilities Performances Evaluation of Sheep Tourism in Garut \\ Regency
}

\author{
Fadila Febianisa Slamet $^{1, a)}$ \& Nurlaila Fadjarwati ${ }^{2, b)}$ \\ ${ }^{1)}$ Program Studi Manajemen Aset, Politeknik Negeri Bandung, Bandung
}

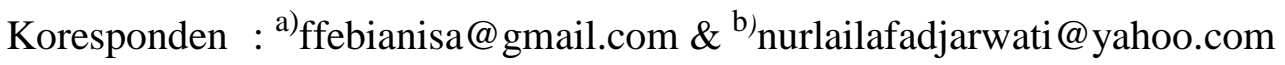

\begin{abstract}
ABSTRAK
Wisata Domba atau De Wisdom merupakan perpaduan wisata alam dan wisata edukasi. Atraksi utama wisata ini adalah peternakan domba dan panorama pegunungan. Wisata Domba beralamat di Kampung Cimuncang, Desa Rancabango, Kecamatan Tarogong Kaler, Kabupaten Garut. Total luas area wisata ini adalah 3 hektar. Makanan yang dijual di De Wisdom Garut sangat minim, pengunjung difabel kesulitan menggunakan toilet, mushola yang tersedia hanya mampu menampung satu orang, pengunjung kesulitan menemukan lokasi setiap fasilitas, sampah berserakan, dan pengunjung difabel seperti tuna netra maupun pengguna kursi roda menggunakan lintasan yang sama dengan pengunjung lainnya. Kinerja aset fasilitas De Wisdom Garut dievaluasi berdasarkan enam aspek yaitu fisik, lingkungan, fasilitas utama, fasilitas pendukung, infrastruktur, dan aksesibilitas. Metode penelitian yang digunakan adalah metode penelitian deskriptif dengan jenis pendekatan kuantitatif dan kualitatif. Teknik pengumpulan data yang digunakan adalah observasi ilmiah, wawancara, studi dokumentasi dan kuesioner. Hasil yang diperoleh dari penelitian ini ialah fasilitas rekreasi di wisata De Wisdom Garut dalam kondisi rusak dan tidak terawat, belum lengkapnya fasilitas utama, fasilitas pendukung, dan infrastruktur. Rekomendasi penyelesaian masalah yang disarankan ialah perencanaan pengembangan aset fasilitas Wisata De Wisdom di Kabupaten Garut.
\end{abstract}

Kata Kunci : manajemen infrastruktur \& fasilitas, evaluasi kinerja, fasilitas pariwisata

\section{PENDAHULUAN}

Wisata Domba atau sering dikenal dengan sebutan De Wisdom adalah salah satu destinasi wisata di Kabupaten Garut yang merupakan perpaduan antara wisata alam dan wisata edukasi. Wisata Domba Garut berada di kaki Gunung Guntur tepatnya di Kampung Cimuncang, Desa Rancabango, Kecamatan Tarogong Kaler, Kabupaten Garut. Total luas wisata ini adalah tiga hektar. Atraksi utama yang dimiliki De Wisdom adalah peternakan Domba Garut. Selain itu, De Wisdom juga menyediakan atraksi alam berupa panorama pegunungan dan perbukitan yang menarik pengunjung. Wisata domba ini merupakan bentuk pengembangan pariwisata berbasis potensi lokal, yakni mengembangkan satuan kawasan wisata dengan objek unggulan wisata alam, budaya, dan buatan (Perda Kabupaten Garut No 29 Tahun 2011).

Saat ini, beberapa fasilitas utama maupun fasilitas pendukung di De Wisdom Garut dalam kondisi rusak, kotor dan tidak terawat, misalnya fasilitas wahana bermain, apartemen domba (kandang), pintu masuk, toilet, dan mushola. Di samping itu, fasilitas area foto dalam keadaan 
rusak sehingga dapat membahayakan pengunjung. Kondisi tersebut dapat ditunjukkan oleh Gambar 1.
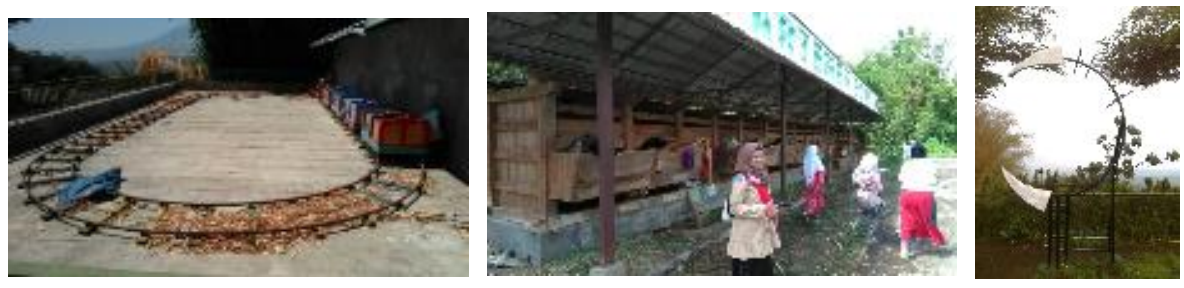

Gambar 1. Kondisi Fasilitas Rekreasi di Wisata Domba

Indikasi masalah lain yang terdapat di De Wisdom Garut ialah makanan dan minuman yang dijual kurang bervariasi, tidak ada toilet khusus untuk penyandang disabilitas, mushola yang tersedia hanya dapat menampung satu orang, dan beberapa titik area De Wisdom ditemukan banyak sampah berserakan. Selain itu, pengunjung juga kesulitan mendapatkan informasi terkait lokasi fasilitas maupun atraksi wisata serta pengunjung difabel baik yang tuna netra maupun pengguna kursi roda menggunakan trek atau lintasan yang sama seperti pengunjung lainnya.

Sebuah aset perlu dikelola secara efektif dan efisien selama umur aset berlangsung. Hal ini bertujuan untuk meminimalkan biaya, menghasilkan keuntungan yang maksimum, serta mengoptimalkan penggunaan dan pemanfaatan aset yang bersangkutan (Sugiama, 2013). Sedangkan tujuan pengelolaan aset menurut Siregar (2004) adalah menjaga nilai ekonomis suatu aset agar bernilai tinggi. Soemitro \& Suprayitno (2018) dan Suprayitno \& Soemitro (2018) juga mengatakan bahwa pengelolaan aset (fasilitas) yang baik tentunya dapat mengurangi atau meminimalisir tingkat risiko yang terjadi.

Tujuan penelitian ini ialah untuk mengevaluasi kinerja aset fasilitas di Wisata Domba Kabupaten Garut sehingga dapat diketahui apakah fungsi aset fasilitas tersebut sudah optimal atau belum serta memberikan solusi atas permasalahan yang terdapat pada obyek yang diteliti. Adapun manfaat penelitian ini adalah dapat dijadikan sebagai rujukan bagi peneliti selanjutnya.

\section{STUDI PUSTAKA}

Infrastruktur merupakan hal yang penting dalam bagian kehidupan ekonomi, sosial, maupun administratif. Infrastruktur perlu dikelola dengan baik agar selalu berfungsi, menghasilkan nilai ekonomis, efektif, efisien, dan berkelanjutan (Soemitro \& Suprayitno, 2018). Campbell et al (2011) mengkategorikan infrastruktur ke dalam jenis/kelas aset. Contoh infrastruktur tersebut antara lain jalur kereta api, distribusi listrik/gas, jalan raya, telekomunikasi, dan air. Adapun Soemitro \& Suprayitno (2018) menyebutkan bahwa infrastruktur erat kaitannya dengan fasilitas, karena fasilitas dapat diartikan sebagai instalasi pelengkap bagi suatu infrastruktur. Sebagai contoh, infrastruktur jalan memiliki beberapa fasilitas seperti rambu dan marka serta fasilitas pelengkap lainnya seperti lampu jalan, trotoar, pagar pengaman jalan, dan sebagainya. Selain itu, fasilitas juga dapat berupa obyek fisik yang diperlukan bagi kehidupan sehari-hari seperti fasilitas kesehatan, fasilitas pendidikan, fasilitas taman hiburan dan lain-lain.

Fasilitas baik itu berupa obyek fisik atau sebagai pelengkap infrastruktur harus di kelola dengan baik agar nilai dari aset (fasilitas) tersebut tidak mengalami penurunan baik dari segi fungsi maupun finansial, sehingga aset yang dimiliki dapat memberikan keuntungan yang optimal. Namun, sebuah aset dapat juga tidak bernilai karena aset tersebut tidak dikelola atau dibiarkan terbengkalai sehingga tidak dapat berfungsi sebagaimana mestinya. Oleh karena itu, guna mengetahui fungsi suatu aset sudah optimal atau belum, maka diperlukan evaluasi kinerja aset yang bersangkutan agar diketahui tindakan apa yang tepat dalam mengelola aset tersebut. Menurut Australian Asset Management Collaborative Group (2008), evaluasi merupakan suatu 
proses yang meliputi pengukuran, pelaporan, dan peninjauan kinerja aset yang dibandingkan dengan pengelolaan aset, tujuan organisasi dan pemerintah. Evaluasi kinerja aset merupakan kegiatan mengidentifikasi dan mencatat semua aset yang dibutuhkan untuk memberikan layanan dan menentukan seberapa efektif aset-aset tersebut mendukung layanan yang dipersyaratkan.

Salah satu contoh fasilitas berupa obyek fisik adalah fasilitas pariwisata. Priskin (2001) berpendapat bahwa ketersediaan fasilitas pada suatu obyek pariwisata dapat meningkatkan kenyamanan dan kepuasan pengunjung atau wisatawan. Menurut Marzuki et al (2017) dan Alaeddinoglu \& Can (2011) terdapat enam aspek yang diukur dalam mengevaluasi kinerja aset fasilitas wisata yakni terdiri dari aspek fisik, lingkungan, fasilitas utama, fasilitas pendukung, infrastruktur, dan aksesibiltas seperti yang ditunjukkan oleh Gambar 2 berikut ini.

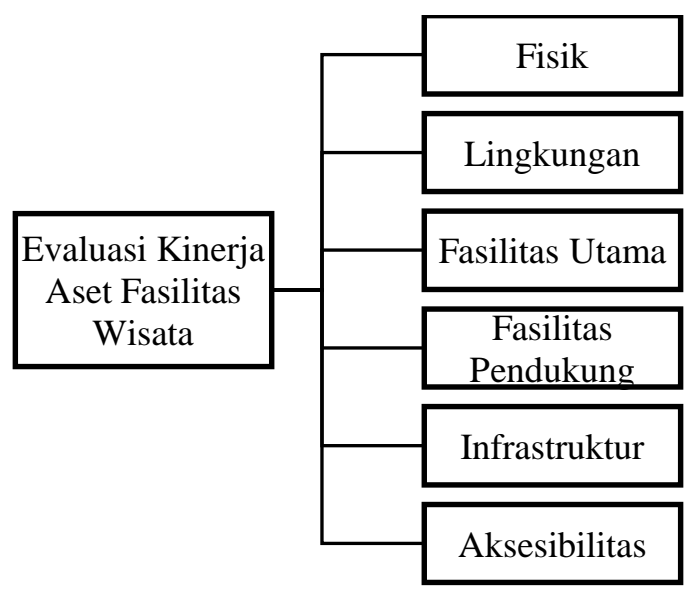

Sumber: Modifikasi Marzuki et al (2017) dan Alaeddinoglu \& Can (2011)

Gambar 2. Evaluasi Kinerja Aset Fasilitas Wisata

\section{Fisik}

Suatu aset perlu dipertahankan dalam kondisi yang memadai untuk memenuhi sasaran dan tujuan yang relevan. Aspek fisik dalam mengavaluasi kinerja sebuah wisata dapat diukur menggunakan tiga indikator yaitu variasi spesies tanaman, variasi aktivitas rekreasi, dan pemandangan.

2. Lingkungan

Aspek lingkungan dapat diukur menggunakan tiga indikator yaitu kebersihan air, tingkat pencemaran udara, dan tingkat pencemaran tanah.

3. Fasilitas Utama

Fasilitas utama dapat diukur menggunakan tiga indikator yaitu tersedianya akomodasi berupa penginapan, rumah makan, dan toilet.

4. Fasilitas Pendukung

Fasilitas pendukung dapat diukur menggunakan delapan indikator yaitu kondisi dan ketersediaan tempat parkir, tempat ibadah, pusat informasi, papan petunjuk, tempat duduk tempat berteduh, toko cinderamata, dan pos keamanan.

5. Infrastruktur

Aspek infrastruktur dapat diukur menggunakan sembilan indikator yakni ketersediaan air, listik, jaringan telekomunikasi, meja piknik, tempat sampah, fasilitas penyandang disabilitas, fasilitas $\mathrm{P} 3 \mathrm{~K}$, dan fasilitas air minum.

6. Aksesbilitas

Aksesibilitas suatu wisata dapat diukur atau dievaluasi dengan menggunakan empat indikator yaitu jarak ke pusat kota, jarak ke sumber daya alam atau sejarah lainnya, tingkat kenyamanan jalan, dan jenis transportasi. 


\section{PENGUMPULAN DATA}

Tujuan penelitian ini adalah mendeskripsikan kinerja aset fasilitas wisata De Wisdom Garut berdasarkan aspek fisik, lingkungan, fasilitas utama, fasilitas pendukung, infrastruktur, dan aksesibiltas serta merumuskan alternatif solusi atas permasalahan yang terjadi pada wisata De Wisdom Garut.

Metode yang digunakan dalam penelitian ini ialah metode deskriptif dengan menggunakan pendekatan kualitatif dan kuantitatif. Menurut Sugiyono (2013) teknik pengumpulan data merupakan langkah strategis dalam penelitian karena tujuan utama dari penelitian adalah mendapatkan data. Data yang dikumpulkan terdiri dari data primer dan data sekunder. Data primer adalah data yang mengacu pada informasi yang diperoleh langsung dari narasumber yang berkaitan dengan masalah yang akan dikaji (Sekaran, 2011). Teknik pengumpulan data primer dalam penelitian ini adalah sebagai berikut:

1. Observasi terhadap ketersediaan dan kondisi aspek fisik, lingkungan, fasilitas utama, fasilitas pendukung, infrastruktur dan aksesibilitas wisata De Wisdom Garut.

2. Wawancara kepada pengelola De Wisdom Garut untuk memperoleh data terkait pengelolaan aset De Wisdom Garut.

3. Kuesioner atau angket yang diisi oleh para pengunjung De Wisdom Garut.

Data sekunder merupakan data yang mengacu pada informasi yang dikumpulkan dari sumber yang telah ada (Sekaran, 2011). Adapun teknik pengumpulan data sekunder dilakukan dengan cara studi dokumentasi guna mengetahui hal-hal yang berhubungan dengan keberadaan aset wisata De Wisdom Garut serta informasi yang dibutuhkan dalam penelitian. Data sekunder tersebut diperoleh dari buku, jurnal, dan peraturan.

Unit analisis dari penelitian ini adalah aset berupa objek wisata De Wisdom Garut. Populasi pada penelitian ini yaitu aset wisata De Wisdom Garut yang meliputi sarana dan prasarananya sehingga teknik pengumpulan data yang digunakan adalah sensus. Selain itu, guna mengetahui kondisi mengenai fasilitas rekreasi dan kondisi jalan di area wisata De Wisdom Garut, maka penelitian ini memakai angket yang didasarkan pada persepsi pengunjung, sehingga membutuhkan sampling. Adapun teknik sampling yang digunakan ialah teknik accidental sampling atau sampling kebetulan, yaitu siapa saja yang secara kebetulan (accidental) bertemu dengan peneliti dapat digunakan sabagai sampel.

Data kuantitatif diolah menggunakan analisis deskriptif dengan bantuan SPSS 24. Ukuran deskriptif untuk data kuantitatif yang digunakan dasar analisis adalah mean atau rata-rata untuk melihat skor atau bobot kepentingan dari indikator yang diteliti. Pengolahan data kualitatif dilakukan secara manual menggunakan tabel silang. Hasil penelitian kuantitatif dan kualitatif menjadi dasar analisis untuk menjawab tujuan dari penelitian ini.

\section{ANALISIS PENELITIAN}

Berdasarkan evaluasi kinerja aset fasilitas De Wisdom Garut yang diukur menggunakan enam aspek yang terdiri dari aspek fisik, lingkungan, fasilitas utama, fasilitas pendukung, infrastruktur, dan aksesibilitas maka hasil dari penelitian ini adalah sebagai berikut:

1. Fisik

Evaluasi kinerja aset fasilitas De Wisdom Garut berdasarkan aspek fisik terdiri dari tiga indikator yaitu variasi spesies tanaman, variasi aktivitas rekreasi, dan pemandangan. Evaluasi aspek fisik tersebut dapat dilihat secara rinci pada Tabel 1 berikut ini. 
Tabel 1. Evaluasi Kinerja Aset Fasilitas De Wisdom Garut Berdasarkan Aspek Fisik

\begin{tabular}{|c|c|c|c|c|}
\hline No & Indikator & Kriteria & Kondisi Eksisting & $\begin{array}{c}\text { Pemenuhan } \\
\text { Kriteria }\end{array}$ \\
\hline 1. & $\begin{array}{l}\text { Variasi } \\
\text { Spesies } \\
\text { Tanaman }\end{array}$ & $\begin{array}{l}\text { Terdapat } \\
\text { beraneka ragam } \\
\text { tumbuhan } \\
\text { seperti } \\
\text { pepohonan dan } \\
\text { tanaman bunga } \\
\text { (Marzuki et al, } \\
\text { 2017) }\end{array}$ & $\begin{array}{l}\text { Spesies atau jenis tanaman yang terdapat di } \\
\text { Wisata De Wisdom Garut sudah bervariasi, } \\
\text { yaitu terdiri dari pepohonan dan tanaman } \\
\text { bunga di antaranya tanaman pisang hias, } \\
\text { pohon cemara norfolk, tanaman bunga } \\
\text { kamboja, pohon palem, tanaman bunga } \\
\text { melati, dan pohon pucuk merah. }\end{array}$ & $\checkmark$ \\
\hline 2. & $\begin{array}{l}\text { Variasi } \\
\text { Aktivitas } \\
\text { Rekreasi }\end{array}$ & $\begin{array}{l}\text { Terdapat } \\
\text { fasilitas rekreasi } \\
\text { seperti arena } \\
\text { bermain untuk } \\
\text { anak atau } \\
\text { keluarga } \\
\text { (Priskin, 2011) }\end{array}$ & $\begin{array}{l}\text { Aktivitas rekreasi yang dapat dilakukan di } \\
\text { wisata De Wisdom Garut ialah berpiknik, } \\
\text { memberi makan domba-domba, belajar } \\
\text { mengenai peternakan domba, bermain di } \\
\text { wahana, dan berfoto. Adapun fasilitas } \\
\text { rekreasi yang tersedia di wisata ini yaitu } \\
\text { arena bermain anak (childrens play), wahana } \\
\text { anak, apartemen domba, kolam buatan, } \\
\text { labirin, dan area berfoto. Namun, sebagian } \\
\text { besar fasilitas rekreasi tersebut rusak dan } \\
\text { tidak terawat. }\end{array}$ & $\mathrm{x}$ \\
\hline 3. & Pemandangan & $\begin{array}{l}\text { Terdapat } \\
\text { pemandangan } \\
\text { atau view yang } \\
\text { dapat dilihat } \\
\text { (Marzuki et al, } \\
\text { 2017) }\end{array}$ & $\begin{array}{l}\text { Terdapat pemandangan alam Gunung Guntur } \\
\text { dan Cikuray. }\end{array}$ & $\checkmark$ \\
\hline
\end{tabular}

Berdasarkan hasil evaluasi aspek fisik, dua indikator yakni variasi tanaman dan variasi aktivitas rekreasi sudah memenuhi kriteria namun, pada indikator variasi aktivitas rekreasi terdapat permasalahan yakni sebagian besar fasilitas rekreasi di wisata tersebut dalam kondisi rusak dan tidak terawat. Hal ini didukung oleh hasil kuesioner responden terhadap fasilitas rekreasi De Wisdom Garut yang dapat dilihat pada Tabel 2.

Tabel 2. Hasil Kuesioner Terhadap Fasilitas Rekreasi di Wisata De Wisdom Garut

\begin{tabular}{|c|l|c|c|}
\hline No & \multicolumn{1}{|c|}{ Fasilitas Rekreasi } & $\begin{array}{c}\text { Hasil Rata-Rata } \\
\text { Kuesioner }\end{array}$ & Keterangan \\
\hline 1. & $\begin{array}{l}\text { Arena Bermain Anak } \\
\text { (Playground) }\end{array}$ & 3,22 & Kurang Nyaman \\
\hline 2. & Wahana Anak & 2,23 & Tidak Nyaman \\
\hline 3. & Labirin & 3,76 & Cukup Nyaman \\
\hline 4. & Apartemen Domba & 2,51 & Tidak Nyaman \\
\hline 5. & Kolam Buatan & 2,23 & Tidak Nyaman \\
\hline 6. & Spot Foto & 3,38 & Cukup Nyaman \\
\hline
\end{tabular}

Berdasarkan tabel tersebut dapat disimpulkan bahwa rata-rata responden atau pengunjung De Wisdom Garut menyatakan tidak nyaman, kurang nyaman, dan cukup nyaman terhadap fasilitas rekreasi De Wisdom Garut.

2. Lingkungan

Evaluasi kinerja aset fasilitas De Wisdom Garut berdasarkan aspek lingkungan terdiri dari tiga indikator yaitu kebersihan air, tingkat pencemaran udara, dan tingkat pencemaran tanah. Evaluasi aspek lingkungan dapat dilihat secara rinci pada Tabel 3 berikut ini. 
Tabel 3. Evaluasi Kinerja Aset Fasilitas De Wisdom Garut Berdasarkan Aspek Lingkungan

\begin{tabular}{|c|c|c|c|c|}
\hline No & Indikator & Kriteria & Kondisi Eksisting & $\begin{array}{c}\text { Pemenuhan } \\
\text { Kriteria }\end{array}$ \\
\hline 1. & $\begin{array}{l}\text { Kebersihan } \\
\text { Air }\end{array}$ & $\begin{array}{ll}- & \text { Air tidak berasa dan } \\
\text { tidak berbau } \\
\text { - } \\
\text { Warna, tingkat } \\
\text { kekeruhan, dan suhu } \\
\text { air tidak melebihi } \\
\text { batas maksimum } \\
\text { (Permenkes No 32 } \\
\text { Tahun 2017) }\end{array}$ & $\begin{array}{l}\text { Kondisi air di De Wisdom } \\
\text { tidak memiliki rasa, tidak } \\
\text { berbau, tidak keruh ataupun } \\
\text { berwarna. }\end{array}$ & $\checkmark$ \\
\hline 2. & $\begin{array}{l}\text { Tingkat } \\
\text { Pencemaran } \\
\text { Udara }\end{array}$ & $\begin{array}{l}\text { Udara tidak berbau dan } \\
\text { tidak ada polusi }\end{array}$ & $\begin{array}{l}\text { Udara sekitar apartemen domba } \\
\text { memiliki bau tidak sedap yang } \\
\text { dapat tercium hingga radius } 7 \\
\text { meter, namun di sekitar fasilitas } \\
\text { rekreasi tersebut terdapat tanaman } \\
\text { kamboja dan melati guna } \\
\text { meminimalisir aroma tidak sedap } \\
\text { yang berasal dari kandang. }\end{array}$ & $\checkmark$ \\
\hline \multirow[t]{2}{*}{3.} & \multirow[t]{2}{*}{$\begin{array}{l}\text { Tingkat } \\
\text { Pencemaran } \\
\text { Tanah }\end{array}$} & $\begin{array}{l}\text { Terdapat biota tanah } \\
\text { yang terdiri dari } \\
\text { tumbuhan dan hewan } \\
\text { berukuran kecil seperti } \\
\text { cacing dan rerumputan } \\
\text { kecil. }\end{array}$ & \multirow[t]{2}{*}{$\begin{array}{l}\text { Area De Wisdom Garut banyak } \\
\text { ditemukan pepohonan dan } \\
\text { tanaman serta rerumputan yang } \\
\text { menujukkan bahwa kondisi tanah } \\
\text { tersebut subur dan tidak tercemar. }\end{array}$} & $\checkmark$ \\
\hline & & $\begin{array}{l}\text { Terdapat banyak ragam } \\
\text { tumbuhan yang hidup } \\
\text { di atas tanah }\end{array}$ & & $\checkmark$ \\
\hline
\end{tabular}

Berdasarkan hasil evaluasi, dapat disimpulkan bahwa kinerja aset fasilitas wisata De Wisdom Garut sudah memenuhi seluruh indikator pada aspek lingkungan. Namun, jumlah tumbuhan terutama tanaman bunga di sekitar Apartemen Domba (kandang) perlu ditambah guna mengurangi bau tidak sedap yang berasal dari kandang tersebut.

3. Fasilitas Utama

Evaluasi kinerja aset fasilitas De Wisdom Garut berdasarkan aspek fasilitas utama terdiri dari tiga indikator yaitu akomodasi, rumah makan, dan toilet. Evaluasi aspek tersebut dapat disajikan pada Tabel 4. 
Tabel 4. Evaluasi Kinerja Aset Fasilitas De Wisdom Garut Berdasarkan Aspek Fasilitas Utama

\begin{tabular}{|c|c|c|c|c|}
\hline No & Indikator & Kriteria & Kondisi Eksisting & $\begin{array}{c}\text { Pemenuhan } \\
\text { Kriteria }\end{array}$ \\
\hline 1. & Akomodasi & $\begin{array}{l}\text { - Tersedia akomodasi } \\
\text { penginapan seperti pondok } \\
\text { wisata, rumah pohon, atau } \\
\text { tenda. } \\
\text { (Permenhut No } 48 \text { Tahun } \\
\text { 2010) }\end{array}$ & $\begin{array}{l}\text { Belum tersedia fasilitas } \\
\text { tempat penginapan di De } \\
\text { Wisdom Garut. }\end{array}$ & $\mathrm{x}$ \\
\hline 2. & $\begin{array}{l}\text { Rumah } \\
\text { Makan }\end{array}$ & $\begin{array}{l}\text { - Tersedia minimum } 5 \text { (lima) } \\
\text { jenis kuliner, maksimum } 20 \\
\text { (dua puluh) jenis kuliner } \\
\text { dan tidak boleh ada } \\
\text { duplikasi. } \\
\text { - Terdapat petunjuk arah dan } \\
\text { papan nama plaza pusat } \\
\text { jajanan/kuliner dengan } \\
\text { tulisan yang terbaca jelas } \\
\text { dan mudah terlihat. } \\
\text { (Permenpar No } 5 \text { Tahun } \\
\text { 2019) }\end{array}$ & $\begin{array}{l}\text { - De Wisdom memiliki } 8 \\
\text { kios kantin, namun kantin } \\
\text { yang beroperasi hanya } 3 . \\
\text { Jenis makanan yang } \\
\text { dijual terdiri dari tiga } \\
\text { variasi } \\
\text { - Tidak ada papan nama } \\
\text { plaza/kuliner sehingga } \\
\text { kios kantin tersebut } \\
\text { belum memenuhi kriteria. }\end{array}$ & $\mathrm{x}$ \\
\hline 3. & Toilet & $\begin{array}{l}\text { - Toilet wanita adalah } 3 \\
\text { (tiga) kali lebih banyak } \\
\text { daripada pria. } \\
\text { - Menyediakan kloset (WC), } \\
\text { urinoir, wastafel, handicap, } \\
\text { toilet paper, } \\
\text { jetspray/washlet, pengering } \\
\text { tangan/tisu, cermin, gayung } \\
\text { dan tempat air, tempat } \\
\text { sampah, saluran } \\
\text { pembuangan, penjaga } \\
\text { toilet, janitor, pintu masuk } \\
\text { utama, kubikal, pintu toilet } \\
\text { untuk orang berkebutuhan } \\
\text { khusus. } \\
\text { (Permenpar No } 5 \text { Tahun } \\
\text { 2019) }\end{array}$ & $\begin{array}{l}\text { - Jumlah toilet wanita dan } \\
\text { pria masing-masing } \\
\text { adalah } 7 \text { dan } 6 . \\
\text { - Terdapat } 6 \text { toilet anak, } 4 \\
\text { di antaranya dalam } \\
\text { kondisi rusak. } \\
\text { - Kelengkapan toilet yang } \\
\text { tersedia terdiri dari } \\
\text { kloset, urinoir, tempat } \\
\text { sampah, cermin, wastafel, } \\
\text { gayung, tempat air, dan } \\
\text { saluran pembuangan air. } \\
\text { - Urinoir dan wastafel } \\
\text { tidak berfungsi. } \\
\text { - Empat toilet pria tidak } \\
\text { tersedia gayung dan } \\
\text { tempat air. } \\
\text { - Tidak ada toilet untuk } \\
\text { penyandang difabel. }\end{array}$ & $\mathrm{x}$ \\
\hline
\end{tabular}

Berdasarkan hasil evaluasi, kinerja aset fasilitas De Wisdom Garut berdasarkan aspek fasilitas utama belum optimal, karena belum tersedia tempat penginapan seperti villa, guest home, dan lainnya. Selain itu, fasilitas rumah makan yang terdapat di wisata De Wisdom Garut masih minim dan tidak terdapat papan nama rumah makan. Selanjutnya, lima toilet anak, wastafel dan urinoir dalam keadaan rusak atau tidak berfungsi, serta kelengkapan toilet pun masih belum memenuhi kriteria.

\section{Fasilitas Pendukung}

Evaluasi kinerja aset fasilitas De Wisdom Garut berdasarkan aspek fasilitas pendukung terdiri dari delapan indikator yaitu tempat parkir, tempat ibadah, pusat informasi, papan petunjuk arah, tempat duduk, tempat berteduh, kios cinderamata, dan pos keamanan. Evaluasi aspek fasilitas pendukung dapat dilihat secara rinci pada Tabel 5 berikut ini. 
Tabel 5. Evaluasi Kinerja Aset Fasilitas De Wisdom Garut Berdasarkan Aspek Fasilitas Pendukung

\begin{tabular}{|c|c|c|c|c|}
\hline No & Indikator & Kriteria & Kondisi Eksisting & $\begin{array}{c}\text { Pemenuhan } \\
\text { Kriteria }\end{array}$ \\
\hline 1. & $\begin{array}{l}\text { Tempat } \\
\text { Parkir }\end{array}$ & $\begin{array}{l}\text { Pengerasan areal harus } \\
\text { menggunakan konstruksi } \\
\text { yang tidak mengganggu } \\
\text { penyerapan air ke dalam } \\
\text { tanah. (Permenpar No } 5 \\
\text { Tahun 2019) }\end{array}$ & $\begin{array}{l}\text { Tersedia areal parkir seluas } 30 \mathrm{~m}^{2} \text {. } \\
\text { Sebagian permukaan areal terbuat } \\
\text { dari paving block dan sebagian } \\
\text { permukaan lain terbuat dari aspal } \\
\text { sehingga memungkinkan penyerapan } \\
\text { air ke dalam tanah terganggu. } \\
\text { Namun, di area parkir De Wisdom } \\
\text { tidak terdapat rambu-rambu parkir } \\
\text { seperti tanda parkir motor atau mobil, } \\
\text { slot parkir, in-masuk, dan } \text { out-keluar. }\end{array}$ & $\mathrm{x}$ \\
\hline 2. & $\begin{array}{l}\text { Tempat } \\
\text { Ibadah }\end{array}$ & $\begin{array}{l}\text { - Luas ruangan dapat } \\
\text { menampung maksimal } 30 \\
\text { orang } \\
\text { - Terdapat penanda arah } \\
\text { yang jelas } \\
\text { (Permenpar No } 5 \text { Tahun 2019) }\end{array}$ & $\begin{array}{l}\text { - Luas mushola hanya } 2 \mathrm{~m}^{2} \\
\text { - Papan nama yang tersedia tidak } \\
\text { terpelihara dan sulit untuk dilihat. }\end{array}$ & $\mathrm{x}$ \\
\hline 3. & $\begin{array}{l}\text { Pusat } \\
\text { Informasi }\end{array}$ & $\begin{array}{l}\text { Tersedia pusat informasi } \\
\text { beserta sarana dan } \\
\text { prasarananya. } \\
\text { (Permenpar No } 5 \text { Tahun } \\
\text { 2019) }\end{array}$ & $\begin{array}{l}\text { Belum tersedia pusat informasi. Saat } \\
\text { ini, fasilitas tersebut masih menyatu } \\
\text { dengan tempat pembelian tiket masuk }\end{array}$ & $\mathrm{x}$ \\
\hline 4. & $\begin{array}{l}\text { Papan } \\
\text { Petunjuk } \\
\text { Arah }\end{array}$ & $\begin{array}{l}\text { - Ditempatkan pada jalan } \\
\text { atau jalan setapak } \\
\text { - Berbentuk trapesium dan } \\
\text { menggunakan simbol } \\
\text { khusus sebagai penjelasan } \\
\text { fasilitas wisata } \\
\text { - Tulisan berwarna putih } \\
\text { dengan latar belakang } \\
\text { coklat } \\
\text { (Permenpar No } 5 \text { Tahun } \\
\text { 2019) }\end{array}$ & $\begin{array}{l}\text { - Papan petunjuk arah yang tersedia } \\
\text { terbuat dari kertas yang lapisi } \\
\text { plastik dan ditempel ditembok. } \\
\text { - Ukuran tulisan papan petujuk arah } \\
\text { terlalu kecil dan tidak dilengkapi } \\
\text { dengan simbol khusus sehingga } \\
\text { kurang informatif. } \\
\text { - Jumlah papan petunjuk arah masih } \\
\text { terbatas. }\end{array}$ & $\mathrm{x}$ \\
\hline 5. & $\begin{array}{l}\text { Tempat } \\
\text { Duduk }\end{array}$ & $\begin{array}{l}\text { - Tempat duduk memiliki } \\
\text { lebar 0,4 m -0,5 m dengan } \\
\text { panjang } 1,5 \mathrm{~m} . \\
\text { - Jarak antara tempat duduk } \\
10 \mathrm{~m} \\
\text { (Permenpar No } 5 \text { Tahun } \\
\text { 2019) }\end{array}$ & $\begin{array}{l}\text { - Tempat duduk berupa bangku } \\
\text { hanya tersedia di area rumah makan } \\
\text { saja sejumlah } 16 \text { buah dengan } \\
\text { kondisi yang kurang terawat. } \\
\text { - Tidak tersedia tempat duduk di } \\
\text { sepanjang jalan setapak. }\end{array}$ & $\mathrm{x}$ \\
\hline 6. & $\begin{array}{l}\text { Tempat } \\
\text { Berteduh }\end{array}$ & $\begin{array}{l}\text { Tersedia tempat berteduh } \\
\text { seperti gazebo, shelter (Bell, } \\
\text { 2008). }\end{array}$ & $\begin{array}{l}\text { Terdapat } 15 \text { gazebo yang terbuat dari } \\
\text { kayu. }\end{array}$ & $\sqrt{ }$ \\
\hline 7. & $\begin{array}{l}\text { Kios } \\
\text { Cinderamata }\end{array}$ & $\begin{array}{l}\text { Tersedia toko cinderamata } \\
\text { (Ginting, 2018) }\end{array}$ & Belum tersedia. & $\mathrm{x}$ \\
\hline 8. & $\begin{array}{l}\text { Fasilitas } \\
\text { Keamanan }\end{array}$ & $\begin{array}{l}\text { Tersedia fasilitas keamanan } \\
\text { seperti pos keamanan, } \\
\text { menara pandang dan alat } \\
\text { pemadam kebakaran. } \\
\text { (Peraturan Dirjen } \\
\text { Perlindungan Hutan dan } \\
\text { Konservasi Alam No } \\
\text { P.02/IV-SET/2012) }\end{array}$ & Belum tersedia fasilitas keamanan & $\mathrm{x}$ \\
\hline
\end{tabular}

Berdasarkan hasil evaluasi, kinerja aset fasilitas De Wisdom Garut belum memenuhi seluruh indikator pada aspek fasilitas pendukung seperti pusat informasi, tempat duduk, kios cinderamata, dan pos keamanan. Adapun fasilitas pendukung yang sudah tersedia belum 
memenuhi kriteria, misalnya luas tempat ibadah yang sempit serta tidak dilengkapi dengan fasilitas penunjang, dan jumlah papan petunjuk yang masih terbatas dan kurang informatif.

5. Infrastruktur

Evaluasi kinerja aset fasilitas De Wisdom Garut berdasarkan aspek infrastruktur terdiri dari delapan indikator yaitu air, listrik, jaringan telekomunikasi, meja piknik, tempat sampah, fasilitas penyandang disabilitas, fasilitas P3K, dan fasilitas air minum. Secara rinci evaluasi aspek tersebut dapat dilihat pada Tabel 6 berikut ini.

Tabel 6. Evaluasi Kinerja Aset Fasilitas De Wisdom Garut Berdasarkan Aspek Infrastruktur

\begin{tabular}{|c|c|c|c|c|}
\hline No & Indikator & Kriteria & Kondisi Eksisting & $\begin{array}{c}\text { Pemenuhan } \\
\text { Kriteria }\end{array}$ \\
\hline 1. & Air & $\begin{array}{l}\text { Tersedia jaringan air } \\
\text { bersih yang mencukupi. } \\
\text { (Permenpar No } 17 \text { Tahun } \\
\text { 2014) }\end{array}$ & $\begin{array}{l}\text { Sudah tersedia jaringan air } \\
\text { besih. }\end{array}$ & $\sqrt{ }$ \\
\hline 2. & Listrik & $\begin{array}{l}\text { Tersedia jaringan listrik } \\
\text { yang mencukupi dan } \\
\text { berfungsi dengan baik. } \\
\text { (Permenpar No } 17 \text { Tahun } \\
\text { 2014) }\end{array}$ & $\begin{array}{l}\text { Jaringan listrik sudah } \\
\text { memadai dan berfungsi } \\
\text { dengan baik. }\end{array}$ & $\checkmark$ \\
\hline 3. & $\begin{array}{l}\text { Jaringan } \\
\text { Telekomunikasi }\end{array}$ & $\begin{array}{l}\text { Tersedia jaringan } \\
\text { telekomunikasi. } \\
\text { (Alaeddinoglu, 2011) }\end{array}$ & $\begin{array}{l}\text { Tersedia jaringan sinyal } \\
\text { telepon. }\end{array}$ & $\checkmark$ \\
\hline 4. & Meja Piknik & $\begin{array}{l}\text { Ukuran meja piknik yaitu } \\
\text { panjang } 1,9 \mathrm{~m} \text { dan lebar } \\
1,5 \mathrm{~m} \text { (Neufert, 2003) }\end{array}$ & $\begin{array}{l}\text { Tersedia } 8 \text { buah meja piknik } \\
\text { dengan ukuran panjang } 2 \mathrm{~m} \\
\text { dan lebar } 1 \mathrm{~m} \text {. }\end{array}$ & $\checkmark$ \\
\hline 5. & Tempat Sampah & $\begin{array}{l}\text { - Tempat sampah } \\
\text { dibedakan berdasarkan } \\
\text { jenis sampah. (Permen } \\
\text { PU No } 3 \text { Tahun 2013) } \\
\text { - Tempat sampah tersedia } \\
\text { dengan jumlah yang } \\
\text { mencukupi dan } \\
\text { diletakkan pada tempat } \\
\text { yang sesuai (Bell, 2008) }\end{array}$ & $\begin{array}{l}\text { - Tempat sampah yang } \\
\text { tersedia belum } \\
\text { berdasarkan jenis sampah. } \\
\text { - Penempatan tempat } \\
\text { sampah belum menyebar } \\
\text { di area wisata De } \\
\text { Wisdom. }\end{array}$ & $\mathrm{X}$ \\
\hline 6. & $\begin{array}{l}\text { Fasilitas } \\
\text { Penyandang } \\
\text { Disabilitas }\end{array}$ & $\begin{array}{l}\text { Tersedia fasilitas bagi } \\
\text { penyandang disabilitas } \\
\text { seperti pintu, tangga, lift } \\
\text { khusus, tempat parkir, } \\
\text { toilet, telepon, peringatan } \\
\text { darurat, rambu, trotoar } \\
\text { khusus penyandang } \\
\text { disabilitas, ramp, dan } \\
\text { tempat duduk. } \\
\text { (Simanjuntak, 2008) }\end{array}$ & $\begin{array}{l}\text { Belum tersedia fasilitas } \\
\text { untuk penyandang disabilitas } \\
\text { di area Wisata Domba. }\end{array}$ & $\mathrm{X}$ \\
\hline 7. & Fasilitas P3K & $\begin{array}{l}\text { Terdapat kotak P3K yang } \\
\text { berisikan alat-alat P3K } \\
\text { yang lengkap. } \\
\text { (Permennakertrans No } 5 \\
\text { Tahun 2008) }\end{array}$ & $\begin{array}{l}\text { Tidak tersedia kotak P3K. } \\
\text { Fasilitas kesehatan yang } \\
\text { tersedia yaitu hanya satu } \\
\text { buah mobil ambulance. }\end{array}$ & $\mathrm{X}$ \\
\hline 8. & $\begin{array}{l}\text { Fasilitas Air } \\
\text { Minum }\end{array}$ & $\begin{array}{l}\text { Terdapat fasilitas tap } \\
\text { water atau keran air } \\
\text { minum } \\
\text { (Alaeddinoglu \& Can } \\
\text { 2011) }\end{array}$ & $\begin{array}{l}\text { Belum tersedia fasilitas air } \\
\text { minum. }\end{array}$ & $\mathrm{X}$ \\
\hline
\end{tabular}


Berdasarkan hasil evaluasi, kinerja aset fasilitas De Wisdom Garut belum memenuhi seluruh indikator pada aspek infrastruktur seperti fasilitas peyandang disabilitas, fasilitas $\mathrm{P} 3 \mathrm{~K}$, dan fasilitas air minum. Adapun fasilitas infrastruktur lain sudah tersedia dan dalam kondisi baik misalnya air, listik, dan jaringan komunikasi, akan tetapi beberapa meja piknik di wisata tersebut dalam kondisi rusak, lokasi penempatan tempat sampah tidak menyebar di seluruh area serta belum dibedakan antara tempat sampah organik dan anorganik.

\section{Aksesibilitas}

Evaluasi kinerja aset fasilitas De Wisdom Garut berdasarkan aspek aksesibilitas terdiri dari empat indikator yaitu jarak ke pusat kota, jarak ke sumber daya alam atau sejarah lainnya, tingkat kenyamanan jalan, dan jenis transportasi. Evaluasi aspek aksesibilitas dapat disajikan pada Tabel 7 berikut ini.

Tabel 7. Evaluasi Kinerja Aset Fasilitas De Wisdom Garut Berdasarkan Aspek Aksesibilitas

\begin{tabular}{|c|c|c|c|c|}
\hline No & Indikator & Kriteria & Kondisi Eksisting & $\begin{array}{c}\text { Pemenuhan } \\
\text { Kriteria }\end{array}$ \\
\hline 1. & $\begin{array}{l}\text { Jarak ke Pusat } \\
\text { Kota }\end{array}$ & $\begin{array}{l}\text { Letak objek wisata } \\
\text { yang dekat dan } \\
\text { mudah diakses dari } \\
\text { pusat kota } \\
\text { (Alaeddinoglu \& } \\
\text { Can, 2011) }\end{array}$ & $\begin{array}{l}\text { Jarak tempuh dari De Wisdom Garut ke } \\
\text { pusat kota yakni Alun-alun Kota Garut } \\
\text { adalah } 6,8 \mathrm{~km} \text { dengan waktu tempuh } 16 \\
\text { menit. Selain itu, wisata De Wisdom } \\
\text { Garut dapat dijangkau dari beberapa } \\
\text { titik seperti Alun-alun Tarogong dan } \\
\text { Kecamatan Samarang dengan jarak } \\
\text { masing-masing } 4,2 \mathrm{~km} \text { dan } 15,4 \mathrm{~km} \text {. } \\
\text { Jarak tempuh tersebut merupakan hasil } \\
\text { pengukuran oleh aplikasi google maps. }\end{array}$ & $\checkmark$ \\
\hline 2. & $\begin{array}{l}\text { Jarak ke Sumber } \\
\text { Daya Alam atau } \\
\text { Sejarah Lainnya }\end{array}$ & $\begin{array}{l}\text { Objek wisata } \\
\text { memiliki jarak yang } \\
\text { dekat dengan sumber } \\
\text { daya alam atau } \\
\text { sejarah lainnya } \\
\text { (Alaeddinoglu \& } \\
\text { Can, 2011) }\end{array}$ & $\begin{array}{l}\text { Cipanas Alam Garut merupakan wisata } \\
\text { daya alam yang paling dekat dengan } \\
\text { wisata De Wisdom Garut dengan jarak } \\
\text { sebesar 3,9 km dan dapat ditempuh } \\
\text { selama } 13 \text { menit dengan menggunakan } \\
\text { transportasi kendaraan mobil. }\end{array}$ & $\checkmark$ \\
\hline 3. & $\begin{array}{l}\text { Tingkat } \\
\text { Kenyamanan } \\
\text { Jalan }\end{array}$ & $\begin{array}{l}\text { Kondisi jalan menuju } \\
\text { wisata De Wisdom } \\
\text { Garut nyaman untuk } \\
\text { dilewati. } \\
\text { (Alaeddinoglu \& } \\
\text { Can, 2011) }\end{array}$ & $\begin{array}{l}\text { Jalan menuju De Wisdom Garut dalam } \\
\text { kondisi baik yaitu permukaan jalan } \\
\text { sudah berbentuk aspal namun, lebar } \\
\text { jalan tersebut termasuk ke dalam } \\
\text { kategori jalan lokal dengan lebar } 10 \\
\text { meter atau hanya memuat } 2 \text { (dua) buah } \\
\text { mobil. }\end{array}$ & $\checkmark$ \\
\hline 4. & Jenis Transportasi & $\begin{array}{l}\text { Jenis transportasi } \\
\text { yang dapat } \\
\text { mengakses objek } \\
\text { terdiri dari kendaraan } \\
\text { pribadi dan } \\
\text { kendaraan umum. } \\
\text { (Alaeddinoglu \& } \\
\text { Can, 2011) }\end{array}$ & $\begin{array}{l}\text { Jenis transportasi yang melewati De } \\
\text { Wisdom Garut dibedakan dari } \\
\text { kendaraan pribadi dan kendaraan } \\
\text { umum. Kendaraan pribadi yang dapat } \\
\text { melewati wisata ini terdiri dari sepeda } \\
\text { motor, mobil penumpang, mobil barang } \\
\text { dan sepeda, sedangkan untuk kendaraan } \\
\text { umum hanya dapat dilalui } \\
\text { menggunakan angkutan online dan } \\
\text { delman. }\end{array}$ & $\checkmark$ \\
\hline
\end{tabular}

Berdasarkan hasil evaluasi, beberapa indikator pada dimensi aksesibilitas sudah memenuhi kriteria yakni dekat dengan pusat kota, dekat dengan sumber daya alam atau tempat sejarah lainnya, serta dapat dilalui oleh kendaraan pribadi dan beberapa kendaraan umum seperti angkutan online dan delman. Namun, tingkat kenyamanan jalan menuju Wisata De Wisdom Garut masih kurang baik, karena jalan yang tersedia hanya dapat dilewati oleh 2 buah mobil. 
Hal ini didukung oleh hasil kuesioner, yakni rata-rata repsonden menunjukkan skor 3,25 yang berati bahwa jalan menuju Wisata De Wisdom Garut cukup nyaman.

\section{KESIMPULAN}

Berdasarkan hasil penelitian dapat disimpulkan bahwa kinerja aset wisata De Wisdom Garut secara keseluruhan masih belum optimal. Hal ini dapat dilihat dari sebagian besar fasilitas rekreasi dalam kondisi rusak dan tidak terawat, jumlah kantin atau kios makanan masih minim sehingga makanan maupun minuman yang dijual kurang bervariasi, lima toilet dan beberapa kelengkapan toilet seperti wastafel dan urinoir dalam kondisi rusak dan tidak berfungsi, tidak ada toilet khusus untuk penyandang cacat, tidak ada rambu-rambu di tempat parkir, tempat ibadah sempit dan tidak ada tempat untuk berwudhu, tempat duduk tidak tersebar di setiap spot wisata, tempat sampah yang tersedia tidak dibedakan antara organik dan anorganik, beberapa meja makan dalam kondisi rusak dan tidak terawat. Selain itu, De Wisdom Garut belum memiliki tempat penginapan, pusat informasi, papan petunjuk, toko cinderamata, pos keamanan, fasilitas untuk penyandang disabilitas, fasilitas $\mathrm{P} 3 \mathrm{~K}$, dan fasilitas air minum.

Dari simpulan di atas, dapat diketahui bahwa permasalahan kondisi fisik berdampak pada kinerja aset fasilitas Wisata De Wisdom Garut. Oleh karena itu, rekomendasi solusi pemecahan masalah yang terjadi pada aset wisata tersebut adalah Perencanaan Pengembangan Aset Fasilitas Wisata De Wisdom di Kabupaten Garut.

\section{DAFTAR PUSTAKA}

Alaeddinoglu, Faruk \& Can, Ali Sekluk. (2011). "Identification and Classification of NatureBased Tourism Resources: Western Lake Van Basin, Turkey". The 2nd International Geography Symposium GEOMED 2010. (19), 198-207. Elsevier.

Australian Asset Management Collaborative Group. (2012). Guide to Integrated Strategic Asset Management. CRC Australia. Brisbane.

Bell, Simon. (2008). Design for Outdoor Recreation (2ndEd). Taylor \& Francis Incorporation. New York.

Campbell, John D., Jardine, Andrew K.S. \& McGlynn, J. (2011). Asset Management Excellence. CRC Press Taylor and Francis Group. United State of America.

Ginting, N \& Sasmita, A. (2018). "Developing Tourism Facilities Based on Geotourism in Silalahi Village, Geopark Toba Caldera”. IOP Conf. Series: Earth and Environmental Science 126 (2018) 012163.

Marzuki, A., Khoshkam, M., Mohamad, D. \& Kadir, I.A. (2017). "Linking Nature-Based Tourism Attributes to Tourists Satisfaction”. An International Journal of Tourism and Hospitality Research. Anatolia, 28:1, 96-99. Routledge.

Neufert, Ernst. (2003). Data Arsitek. Erlangga. Jakarta.

PerDaKab Garut (2011). Peraturan Daerah Kabupaten Garut Nomor 29 Tahun 2011 tentang Rencana Tata Ruang Wilayah Kabupaten Garut Tahun 2011 - 2031.

PerDirjen 02/12. Peraturan Direktur Jendral Perlindungan Hutan dan Konservasi Alam No P.02/IVSET/2012 tentang Pembangunan Sarana Pariwisata Alam di Taman Nasional, Taman Hutan Raya dan Taman Wisata Alam.

PerMenHut 48/10. Peraturan Menteri Kehutanan Republik Indonesia Nomor P.48/MenhutII/2010 tentang Pengusahaan Pariwisata Alam di Suaka Margasatwa, Taman Nasional, Taman Hutan Raya, dan Taman Wisata Alam.

PerMenKes 32/17. Peraturan Menteri Kesehatan Republik Indonesia Nomor 32 Tahun 2017 tentang Standar Baku Mutu Kesehatan Lingkungan dan Persyaratan Kesehatan Air untuk Keperluan Higiene Sanitasi, Kolam Renang, Solus Per Aqua, dan Pemandian Umum 
PerMenNakerTrans 15/08. Peraturan Menteri Tenaga Kerja dan Transmigrasi Republik Indonesia Nomor PER.15/MEN/VIII/2008 tentang Pertolongan Pertama Pada Kecelakaan di Tempat Kerja.

PerMenPar 17/14. Peraturan Menteri Pariwisata dan Ekonomi Kreatif Republik Indonesia Nomor 17 Tahun 2014 tentang Standar Usaha Kawasan Pariwisata.

PerMenPar 5/19. Peraturan Menteri Pariwisata Republik Indonesia Nomor 5 Tahun 2019 tentang Petunjuk Operasional Pengelolaan Dana Alokasi Khusus Fisik Bidang Pariwisata.

PerMenPU 3/13. Peraturan Menteri Pekerjaan Umum Republik Indonesia Nomor 03/PRT/M2013 tentang Penyelenggaraan Prasarana dan Sarana Persampahan dalam Penanganan Sampah Rumah Tangga dan Sampah Sejenis Sampah Rumah Tangga

Priskin, Julianna. (2001). "Assessment of Natural Resources for Nature-Based Tourism: The Case of The Central Coast Region of Western Australia". Journal of Tourism Management, 22, 637-648. Pergamon. Australia.

Sekaran, U. (2011). Metode Penelitian untuk Bisnis. Salemba Empat. Jakarta.

Simanjuntak dkk. 2018. "Penyediaan Aksesibilitas Bagi Wisatawan Penyandang Disabilitas oleh Stakeholder di Kotamadya Denpasar Kecamatan Denpasar Selatan”. Jurnal IPTA. Volume 6, Nomor 1, 2018, hal. 55-69.

Siregar, D. (2004). Manajemen Aset. Gramedia Pustaka Utama. Jakarta.

Soemitro, R. A. A., \& Suprayitno, H. (2018). "Pemikiran Awal tentang Konsep Dasar Manajemen Aset Fasilitas". Jurnal Manajemen Aset Infrastruktur \& Fasilitas, Vol.2, Sup.1, Juni 2018, Hal. : 1 -10.

Sugiama, A. G. (2013). Manajemen Aset Pariwisata. Guardaya Intimarta. Bandung.

Sugiyono. (2017). Metode Penelitian Administrasi. CV Alfabeta. Bandung.

Suprayitno, H., \& Soemitro, R. A. A. (2018). "Preliminary Reflexion on Basic Principle of Infrastructure Asset Management". Jurnal Manajemen Aset Infrastruktur \& Fasilitas, Vol.2, No.1, Maret 2018, Hal. : 1-10. 